No. 4575 July 6, 1957

\section{Canadian Journal of Chemical Engineering}

IN recognition of the growth of the chemical engineering profession in Canada the Chemical Institute of Canada is publishing a new journal, The Canadian Journal of Chemical Engineering, the first issue of which appeared in June. In publishing this new journal, the Institute has taken over the Canadian Journal of Technology, which was published by the National Research Council. The conversion and renaming of this long-established journal is designed to provide additional service to the chemical engineering members of the Institute, and to provide a medium of publication for the increasing amount of chemical engineering research and development that is being carried out in Canada. The Canadian Journal of Chemical Engineering, which will be published every second month, is edited by W. M. Campbell, of the Chemistry and Metallurgy Division, Atomic Energy of Canada, Ltd., Chalk River. Subscription rates are 3 dollars a year; U.K. and U.S.A., 4 dollars; foreign, 4.50 dollars ; single copies, $75 \mathrm{c}$.

\section{Transatlantic Travel}

Political and Eeonomic Planning published "Transatlantic Travel" (Broadsheet No. 410. Pp. 85-108. 2s. 6d.) on May 20, before the Chancellor of the Exchequer announced on June 4 that the ordinary travel allowance, at present $£ 100$ a year, would be available in future for travel to the dollar area, in the same manner as for travel in the transferable account area. The Chancellor attempted no estimate of the cost of this relaxation, but the Broadsheet estimates that for an additional dollar cost of $£ 5$ million, $40,000-50,000$ more people could visit the United States and Canada each year. The Broadsheet, which includes a list of opportunities for study and travel in the United States and Canada, points out that whereas in $1956,576,000$ United States residents visited Europe, of whom 250,000 visited Britain, spending more than 80 million dollars-or 130 million dollars if travel is includedthe total annual movement from Britain to the United States in recent years averaged about 37,000 , of whom 10,000 were in transit to Australia or the Far East. Of the remainder, 8,500 were business men, about 1,200 had government or official visas, and 1,000 were on 'exchange' visas, mainly university professors or students. The total cost of travel abroad in 1956 was $£ 123$ million, of which travel to the dollar area represented $£ 5$ million, about onethird being in Canada and two-thirds in the United States. The Broadsheet is critical of other obstacles to travel, such as the visas required by the United States, and the rigorous regulations which must be satisfied before a visit to Canada is allowed. It also concludes that there is a strong case for extending the teacher-exchange scheme to other professions, and recommends establishment of a comprehensive agency with both the United States and Canada to foster such exchanges. Cheaper transport would facilitate a wider extension of university interchange, and much more could be done to encourage transatlantic travel for students.

\section{A New Ferroelectric Material}

Progress continues to be made with both methods and materials for the storage of digital information. Recently the Massachusetts Institute of Technology made use of superconductivity in a storage element called a 'cryotron' which occupies little more than
$0.01 \mathrm{~cm}^{3}$ per binary digit (bit). Now the Bell Telephone Laboratories, New York, have announced a new ferroelectric material, triglycine sulphate, particularly suited to switching and storage. Its coercive electric field is $220 \mathrm{~V}$. $/ \mathrm{cm}$., only one-fifth that of either barium titanate, the most widely studied ferroelectric material, or guanidinium aluminium sulphate hexahydrate (G.A.S.H.), a material described earlier by the Bell Telephone Laboratories. The Curie point of the new material is $47^{\circ} \mathrm{C}$. (that of barium titanate being about $120^{\circ} \mathrm{C}$, and of guanidinium aluminium sulphate hexahydrate not less than $200^{\circ} \mathrm{C}$.), but can be raised to $60^{\circ} \mathrm{C}$. or more by substituting deuterium for some of the hydrogen atoms. Switching times of a microsecond or two, such as have been realized also with barium titanate, are claimed (guanidinium aluminium sulphate hexahydrate responds much more slowly). Triglycine sulphate does not show the fatigue found in barium titanate after repeated switching, and will retain its polarization for long periods. When a wafer, $1 \mathrm{~cm}$. square and $0.02 \mathrm{~cm}$. thick, has a set of ten parallel strips of metal evaporated on to each of its two large faces, one set at right angles to the other, it can store 100 bits and be driven and read by circuits using transistors. The material is chemically stable, does not decompose on exposure to the air, and can be handled in thin sheets-three valuable secondary properties.

\section{North Pacific Volcanoes}

Is the past two years studies by American and by Russian geologists have added greatly to our knowledge of the island arc volcanoes of the northern Pacific. In co-operation with the Department of Defense, the United States Geological Survey has lately completed an investigation of the eruptive centres of Alaska, the Aleutian islands, and the Pribilof archipelago " "Investigations of Alaskan Volcanoes", Bull. U.S. Geol. Surv., No. 1028 A-F, 1955-56. Pp. $160+21$ plates +36 figs.); while simultaneously the results of comparable work on volcanic and hydrothermal activity in Kamchatka and the Kurile Islands has been published in Moscow by the Academy of Sciences (Trudy Laboratorii Vulkanologii, No. 10, 82, 1955; No. 12, 218, 1956). In the Pribilof group, described by T. F. W. Barth (Bull., $1028 F^{\prime}$ ), the rocks differ from the andesites and basalts of the other volcanic centres in showing alkalic affinities, the basic lavas and tuffs being predominantly basanitic, sometimes with olivine bombs which are presumed to be derived from an exposed periodotite basement. The lengthy studies of Kamchatkan and Kurile volcanoes are replete with petrographical detail and in particular they give much new information on the composition of fumarolic gases. Surprisingly, neither the Russian nor the American authors refer to previous work by their national counterparts.

\section{A Geological Garden}

A GEOlogical garden construeted at Loeds by Dr. D. E. Owen is described in the issue of the Museums Journal for May 1957. A site within the grounds of Kirkstall Abbey was made available, and an outline map of England and Wales was marked by an 18-in. concrete path. Large, typical, clean, unweathered and uncut specimens of rocks measuring $3 \mathrm{ft} . \times$ $1 \mathrm{ft} .6 \mathrm{in}$. were then placed in their correct relative positions. Individual labels giving the name of the 